\title{
Implementation of Importance Performance Analysis Methods as Government Internal Supervisory Apparatus (GISA) Performance Measurements in Indonesian Provinces
}

\author{
Amir Indrabudiman, Wuri Septi Handayani, Dewi Puspaningtyas Faeni
}

\begin{abstract}
Government Internal Supervisory Apparatus (GISA) is a government agency that has the task of internal supervision include: Audit, Review and Planning, evaluation, monitoring, consulting, assistance and oversight activities of other, shall comply with the code of ethics of internal auditors in the government of Indonesia which contains the rules of conduct and ethics in order to provide added value for effectiveness and efficiency organization. Therefore, by implementing the Code of Ethics for auditors who are the subject of particular scrutiny, will certainly help the organization / institution in realizing good governance as part of a national duty. The purposes of this research are to analyze the performance of Government Internal Supervisory Apparatus (GISA) in order to realize Good Governance in Indonesian Provinces. The method of this research is a Survey and instrument of analysis employed is Importance Performance Analysis (IPA) with 123 respondents District/City Government in Jakarta, Banten and West Java. The gap between importance and performance from both perspectives were also evaluated. The findings of this study will be applied to improve performance of Government Internal Supervisory Apparatus (GISA) in order to realize Good Governance in Indonesian Provinces.
\end{abstract}

\section{Introduction}

Government Internal Supervisory Apparatus (GISA), which is an integral part of the internal control systems of government agencies (SPIP), supposedly a bastion of the first in preventing cases of Corruption (TPK) in each of their institutions, both ministries / agencies and local governments. While on the other hand, prevention efforts undertaken by the Government Internal Supervisory Apparatus (GISA) have not shown encouraging results. How many cases involving the helm of the Ministry / Agency and local government supervision escaped the GISA. With its capacity, GISA should be able to prevent the

Meaning of level 1 is GISA has been unable to

Revised Manuscript Received on July 05, 2019.

Amir Indrabudiman,

Doctoral Student in Accounting Sciences at Universitas Padjadjaran, Bandung, Indonesia,

amir.indrabudiman@budiluhur.ac.id
TKP through its oversight role, both in the field of auditing, the Review, evaluation, and monitoring (BPKP, 2013: 21) [1-2].

Region I Director, Deputy Head of BPKP, Dodi Setiadi while opening the Auditor GISA Development Forum and workshop December 9, 2014, states: "Efforts to strengthen the internal control needs to be continued. Much has to be done by the Government Internal Supervisory Apparatus (GISA) and many that must be addressed, because of the many demands of change and social dynamics. (Bpkp.go.id, 2014). The results of the mapping capability GISA conducted by BPKP, to 2013 against 396 units nationally GISA is as in the following graph:

Region I Director, Deputy Head of BPKP, Dodi Setiadi while opening the Auditor GISA Development Forum and workshop December 9, 2014, states: "Efforts to strengthen the internal control needs to be continued. Much has to be done by the Government Internal Supervisory Apparatus (GISA) and many that must be addressed, because of the many demands of change and social dynamics. (Bpkp.go.id,

2014). The results of the mapping capability GISA conducted by BPKP, to 2013 against 396 units nationally GISA is as in the following graph: [3-5]

Figure 1.Mapping GISA Capability by BPKP in 2013

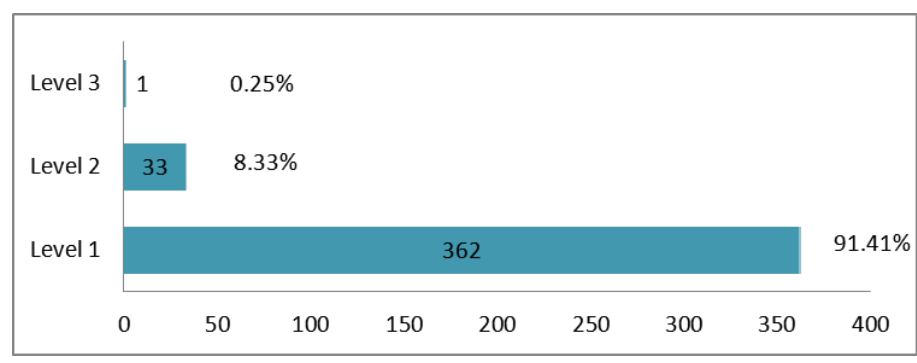

provide assurance that the program or activity conducted by the Government accordance with the legislation. GISA has not

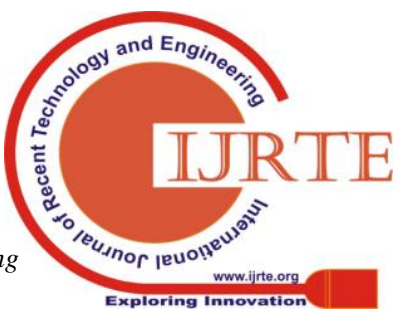


Implementation of Importance Performance Analysis Methods as Government Internal Supervisory Apparatus (GISA) Performance Measurements in Indonesian Provinces

been able to prevent corruption. GISA has not been able to provide assurance on the efficiency and effectiveness of programs / activities of the Government. Level 2 is where GISA able to provide reasonable assurance that programs or activities undertaken by the Government in accordance with the legislation and GISA has been able to detect the occurrence of corruption. While level 3 where GISA able to assess the efficiency, effectiveness and economical it's an activity and is able to provide consulting on corporate governance, risk management and internal control. At level 3 has to be said is this GISA GISA Effective in accordance with Article 11 of Government Regulation No. 60 of 2008 (bpkp.go.id, 2014) [6].

Then on January 5, 2015, BPKP published the results of a satisfaction survey of government agencies on certified auditors against GISA 433 units, with a scale of 1 to 10 , the results are as follows:

Table 1.Satisfaction Survey Top Government Agencies Certified Auditor

\begin{tabular}{|c|c|c|c|}
\hline No. & Question / Statement & Average & Results \\
\hline 1. & Auditor competence. & 7.54 & Not eligible \\
\hline 2. & Willingness auditor develop professionalism. & 7.84 & Eligible \\
\hline 3. & Timely release monitoring reports. & 7.08 & Not eligible \\
\hline 4. & The quality of the audit report. & 7.35 & Not eligible \\
\hline 5. & The quality of the preparation of supervisory findings. & 7.79 & Eligible \\
\hline 6. & Adherence to the standard auditor. & 7.64 & Eligible \\
\hline 7. & Adherence to the code of ethics of auditors / rules of conduct. & 7.73 & Eligible \\
\hline 8. & Benefits for agency performance. & 7.96 & Eligible \\
\hline 9. & The efficiency of the implementation of the work. & 7.59 & Not eligible \\
\hline Ave & & 7.61 & Eligible \\
\hline
\end{tabular}

Facts on Figure 1 and Table 1 shows the role of GISA is not optimal due to auditor competence, punctuality and quality reports, as well as the duration of the implementation of the auditor's work. The former finance minister, Basri when opening the Conference of the Association of Internal Auditors Government of Indonesia (27/08/2013) says: "Expect the GISA empowerment in improving the quality of public finance management are not only limited to conduct an audit, but also function as a catalyst and consultants who can push improving the quality of public finance management. Supervision is not only done on the implementation and accountability of the budget, but also in the stage of planning and budgeting so that preventive action.

Related accountability, Basri said: "Expect to be GISA can guarantee that the whole process of accounting and financial reporting has been implemented in accordance with Government Accounting Standards. GISA is not just merely reviewing the financial statements, but should also help units that have constraints in dealing with problems of financial accountability, including mentoring during the financial audit by external auditors (Warta Pengawasan, 2013) [7].

Based on the problems that have been expressed, not optimal performance of the supervisory cause problems accountability in the management of state finances.

Problem in this study can be formulated as follows: 1) Which GISA performance attributes in incoming quadrant A (Concentrate here), B (Keep up the good work), C (Low priority), and D (Possible Overkill)? 2) Does the performance of Government Internal
Supervisory Apparatus (GISA) has been in line with expectations?

\section{Literature Review}

Officials Internal Control Government or supervisor intern at another institution, hereinafter referred GISA is the apparatus that perform oversight through audits, the Review, evaluation, monitoring and supervisory activities other against the implementation of tasks and functions of the organization. Indonesian Government Regulation No. 40 of 2010 stipulates the criteria of functional skills and functional skills to have professional ethics established by professional organizations. Professional ethics are the norms or rules laid down by scientific disciplines and professional organizations to be followed by functional officials in carrying out their duties and responsibilities. The code of ethics of internal auditor's Indonesian government included two basic components, namely: 1) the ethical principles that are relevant to the profession and practice of internal control of government, and 2) Rules of conduct that describe behaviour norms expected for internal auditors in government in fulfilling their professional responsibilities, with details as follows [8]:

\subsection{Integrity}

Integrity is the quality, nature, or the circumstances indicate a unified whole that has the potential and ability that exudes dignity and honesty. The integrity of the government's internal auditor build trust and thus provides the basis for confidence in its consideration. Integrity is not only expressed

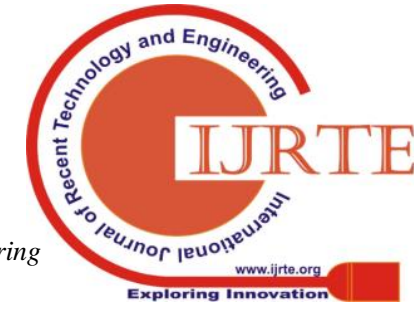


honesty, but also a reasonable relationship and the actual situation [9].

\subsection{Objectivity}

Objectivity is honest attitude that is not influenced by the opinion and consideration of personal or group in taking a decision or action. The government's internal auditor showed the highest level of professional objectivity in gathering, evaluating, and communicating information about the activity or process being audited. Government internal auditors make impartial assessment of all the relevant circumstances and are not affected by its own interests or anyone else in making judgments. The principle of objectivity determines the obligation of the government's internal auditor to be candid, intellectually honest and free of interest [10].

\subsection{Confidentiality}

Confidentiality is the nature of something entrusted to someone that was not told to anyone else who is not authorized to know. Government internal auditors respect the value and ownership of information received and do not disclose information without proper authority, unless there are statutory provisions or professional obligation to do so.

\subsection{Competence}

Competence is the ability and characteristics possessed by a person, in the form of knowledge, skills, and attitudes necessary behaviour in the execution of his duties. Government internal auditors apply the knowledge, expertise and skills, and experience in the implementation of internal oversight services.

\subsection{Accountable}

Accountability is the ability to deliver accountability or to address the performance and actions of a person to the party who has the right or in authority to request information or accountability. To apply principles of accountable, the government's internal auditor shall deliver accountability or answers and information on the performance and actions individually or collectively to those who have the right to request information or accountability.

\subsection{Professional Conduct}

Professional behaviour is behaviour that is characteristic, quality, and the quality of a profession or a professional person which requires a knack for it to run. Government internal auditors should act in a manner consistent with the good reputation of the profession and refrain from any behaviour that may eliminate the trust to the profession of internal control or organization [11].

\section{Research Methods}

This research was conducted at the Provincial Government, District and City in Jakarta, Banten and West Java in the period November 2016-January 2017. The method in this study is a survey using a questionnaire to the 123 people who have been tested for validity and reliability. The scale used to measure the respondents' answers are likert a scale of 1-5.

Sample/unit of analysis in this study were selected based on the following reasons: 1) BPK's audit findings on IHPS 12015 indicates that the local government (LG) is the most problematic than the central government, state enterprises and other entities with a number of findings of 8019 from a total of 10,154 findings or equivalent $78.9 \%$. 2) Inspection Report (LHP) in IHPS 12015 on local government performance audit, it is done in DKI Jakarta and West Java (Bogor and Depok). 3) The main problem and the greatest value Inspection with Specific Purpose (PDTT) in IHPS 12015 was DKI Jakarta province, coupled with the collapse of the political dynasty (Ratu Atut) that controls Banten province. This is the reason the province (DKI Jakarta, Banten and West Java) have been selected as the unit of analysis in this study.

Data were analysed using Importance Performance Analysis (IPA). To describe the expectations and the reality of the preferences of the respondents in the form of Cartesian diagram as follows

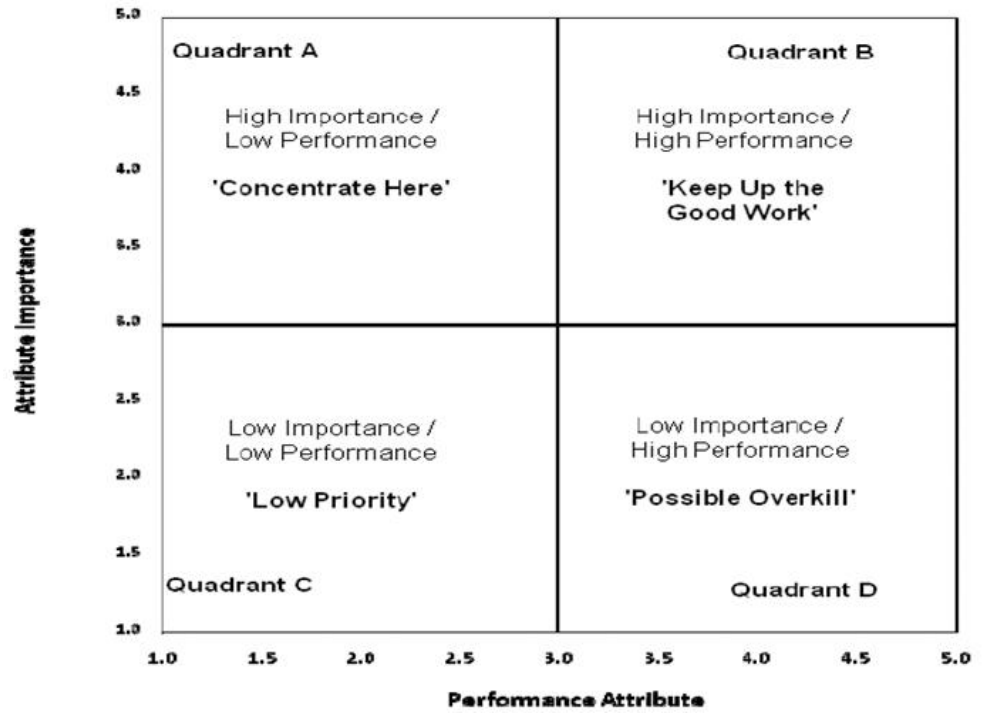

Figure 2. Importance Performance Analysis 
Implementation of Importance Performance Analysis Methods as Government Internal Supervisory Apparatus (GISA) Performance Measurements in Indonesian Provinces

Source: Martilla \& James (1977:78).

Quadrant A shows the factors that are considered very important, but the GISA has not carried out as you wish / hope. Quadrant B shows the factors that are considered important, has been successfully implemented in accordance GISA wishes / expectations and very satisfying so shall be maintained. Quadrant C shows the factors that are considered less important, implementation was undertaken by GISA are adequate or mediocre. Quadrant D show a less important factor, but the implementation is excessive / very satisfactory.

Calculation of suitability is a comparison between the level of interest / expectations (importance) to the level of performance. Concordance rate is what will determine the order of priority of improving the factors that can affect the quality of service. The formula used is:

\section{$\sum x$}

SLi $=----------X 100 \%$

$\sum \mathrm{Yi}$

Where:

SLi: Suitability level respondents

Xi: performance assessment score.

Yi: importance assessment score.
Based on calculations Important Performance Analysis (IPA) obtained an average value of performance (performance) and the average value expectations (importance) of each indicator GISA performance shown in appendix and Cartesian diagrams as follows:

\subsection{Integrity}

In quadrant $A$ shows the factors considered to affect the performance of GISA, these factors are considered very important, but the GISA has not done in line with expectations. The factors included in quadrant $A$ is: Honest, Persevering and Obeying the law. This means that GISA had been doing the work honestly and diligently, and obey the law and make disclosures that are required by the provisions of law and the profession. Quadrant B demonstrated performance factors that have been successfully implemented by GISA, which is to be responsible, meaning that GISA had done the job with responsibility. This should always be maintained by GISA because it is considered a very important and very satisfying. Quadrant $C$ shows the factors that are considered less important influence on performance is Gratification, meaning GISA does not accept gratuities with a position in any form. Quadrant D indicates a less important factor in influencing the performance, but the implementation is very satisfactory given GISA, the organization goals, meaning that GISA had respect and contribute to the organization's goals are legitimate and ethical.

\section{Results and Discussion}

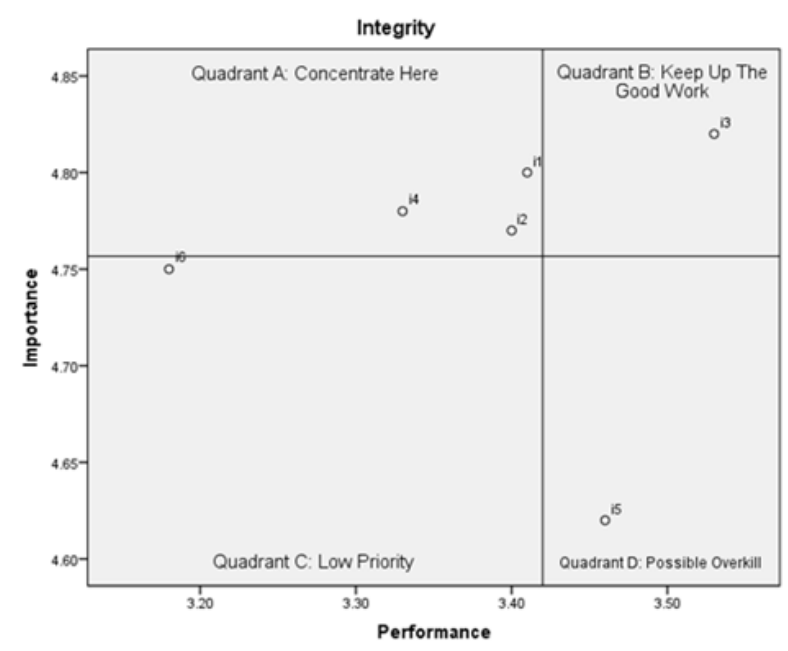

Figure 3. Importance Performance Analysis of Integrity Source: SPSS Output.

\subsection{Objectivity}

Professional judgment entered in quadrant $A$, which means do not receive anything in any form that could interfere or reasonably suspected to interfere with professional judgment is a factor that is a top priority in performance. Material facts included in quadrant $B$, which means that GISA had managed to disclose all known material facts, namely the fact that if disclosed could change or influence decisions or cover up their practices that violate the law. This should be maintained. Conflict of interest and prejudice there is in quadrant $\mathrm{C}$, which means not participating in activities or relationships

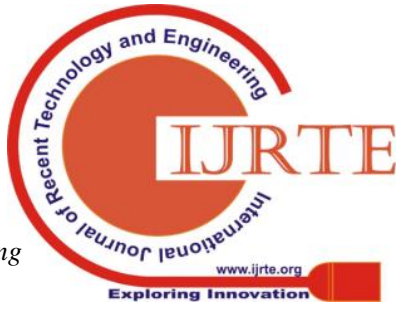


that might conflict with the interests of the organization and could prejudice a less important factor in performance. Professional responsibility contained in quadrant $\mathrm{D}$, meaning not participate in activities or relationships that doubted his ability to be able to perform their duties and fulfil the objective of professional responsibility is a factor that is considered less important but execution granted by GISA very satisfactory or too excessive.

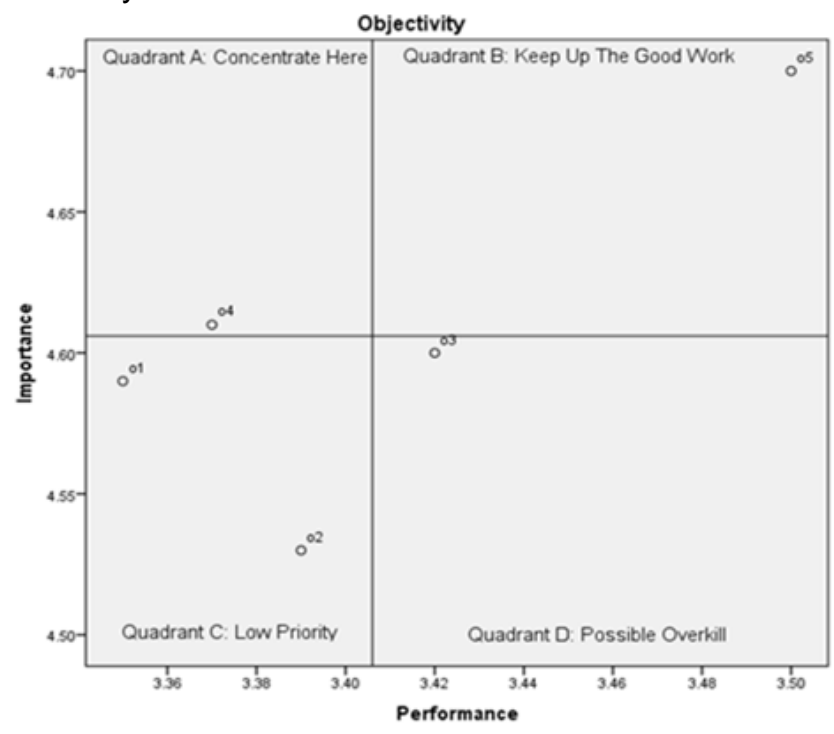

Figure 4. Importance Performance Analysis of Objectivity Source: SPSS Output.

\subsection{Secrecy}

Misuse of the information contained in the second quadrant $A$, meaning GISA not use the information in any way that would be contrary to the statutory provisions.

This is a priority that affects performance and is very important. Use of information and protecting information is in quadrant $B$, which means GISA Be careful in the use of information obtained in his duties and Exercise caution in protecting information obtained in its work.

Therefore, it should always be maintained. Misuse of information ( 1 and 3 ) is in quadrant $C$, meaning GISA not use the information for personal gain and not use the information in any way that would be detrimental to the organization's goals are legitimate and ethical.

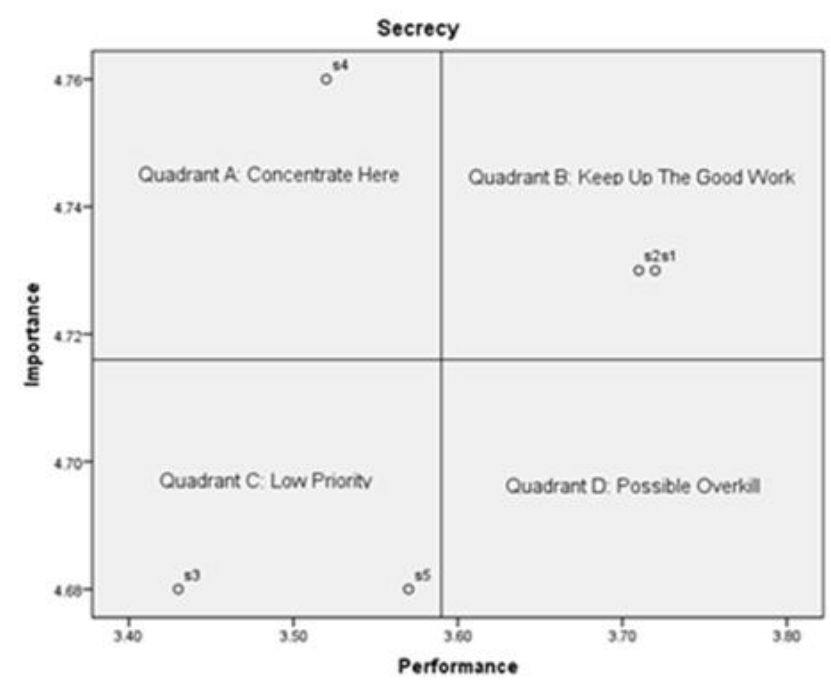

Figure 5. Importance Performance Analysis of Objectivity Source: SPSS Output.

\subsection{Competence}

Knowledge is in quadrant A, meaning GISA Constantly improving skills and the effectiveness and quality of execution of their duties with formal education. It is considered very important, but the GISA has not done in line with expectations. So, increasing the membership should be a 
Implementation of Importance Performance Analysis Methods as Government Internal Supervisory Apparatus

(GISA) Performance Measurements in Indonesian Provinces

top priority. Quadrant B shows the factors that have successfully implemented very well. That is GISA constantly improve skills and the effectiveness and quality of execution of their duties with the certification. Therefore, Expertise must always be maintained. Skill is in quadrant C, meaning GISA constantly improve skills and the effectiveness and quality of the performance of its duties by training. Although considered less important and less satisfying, but it remains a priority for improvement. In quadrant $D$, which means there is attitude behaviour GISA already providing services which can be solved long as they have the knowledge, expertise and skills, and experience needed. This has been demonstrated by GISA very satisfactorily but is considered less important

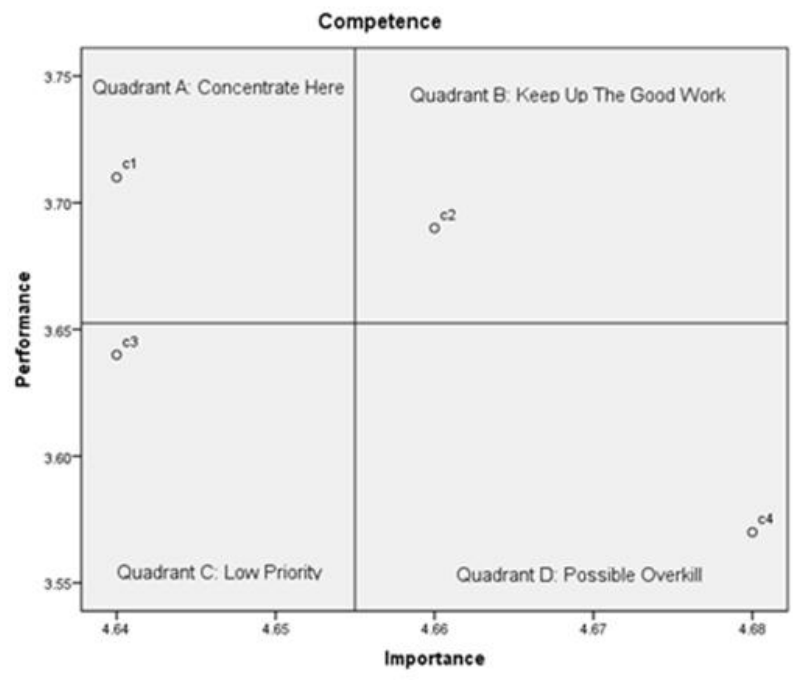

Figure 6. Importance Performance Analysis of Competence Source: SPSS Output.

\subsection{Accountable}

Ability deliver accountability are in quadrant B, meaning that GISA had been doing surveillance in accordance with Indonesian Government Internal Audit Standards. So, this factor should always be maintained.

In quadrant $C$, are abilities to answer to the party entitled / authorized, meaning that GISA had the ability to pass on responsibility to the party who has the right or in authority to request information or accountability. But still considered less important and less satisfying.

The ability of a person's performance and conduct are in quadrant $\mathrm{D}$, meaning that GISA had the ability to respond to those in authority have a right to request information or accountability. This factor is less important but very satisfying.

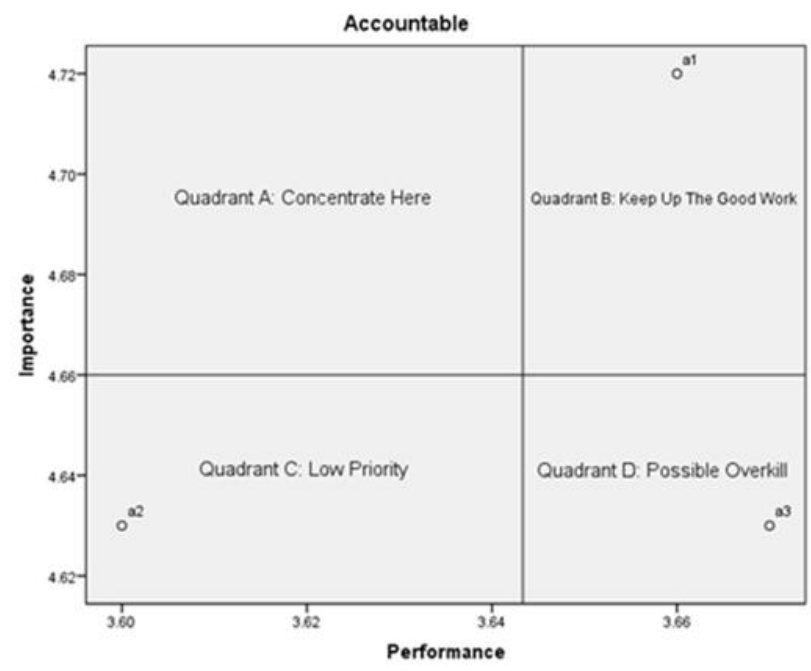

Figure 7. Importance Performance Analysis of Accountable Source: SPSS Output. 


\subsection{Professional behaviour}

Illegal Activities are in quadrant $A$, meaning that GISA was not involved in any illegal activity. This factor is considered very important in influencing the performance, but has not been implemented as expected. In quadrant $B$ are trusts profession and consultation, meaning GISA not engage in any action that removes the trust to the profession of internal control or organization and does not take over the role, duties, functions and responsibilities of the audited management in performing the duties that is consultation. Both of these factors have been successfully implemented by GISA and are considered very important, so it should always be maintained. Reputation of the profession included in quadrant $D$, which means that this factor is less important, but the implementation is given satisfactory. GISA has the ability to explain the performance and actions of a person to the party who has the right or in authority to request information or accountability.

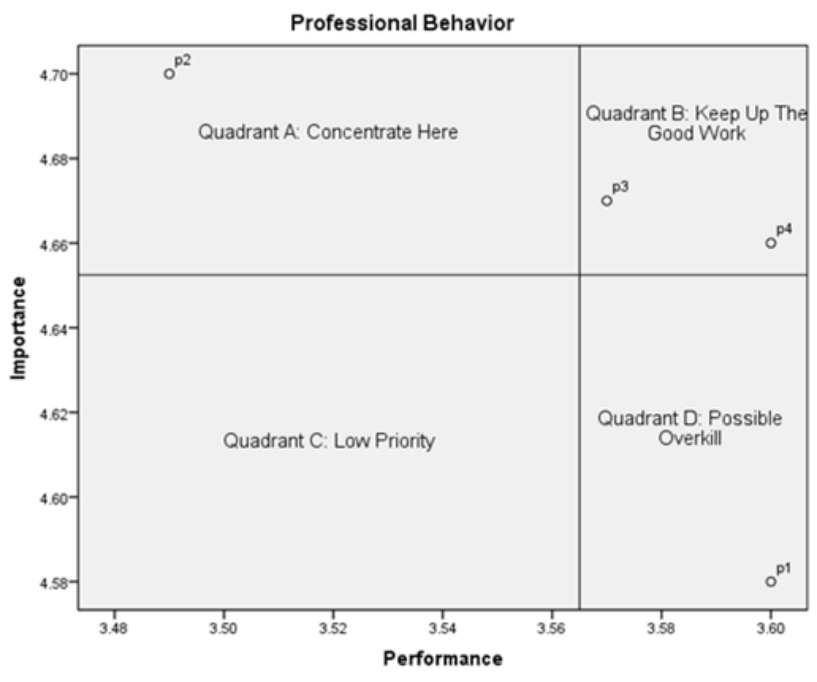

Figure 8. Importance Performance Analysis of Professional Behavior Source: SPSS Output.

4.7. Overall

Results of the performance analysis performance and suitability level calculation is as follows:

Table 1.SEEPSTitability Level of GISA Performance

\begin{tabular}{lccccc} 
& Performance Importance Suitability Level & Quadrant & Strategy \\
\hline Integrity & 3.39 & 4.76 & $71.16 \%$ & A & Concentrate here \\
Objectivity & 3.41 & 4.61 & $73.95 \%$ & C & Low priority \\
Secrecy & 3.59 & 4.72 & $76.12 \%$ & B & Keep up the good work \\
Competence & 3.65 & 4.66 & $78.46 \%$ & D & Possible overkill \\
Accountable & 3.64 & 4.66 & $78.18 \%$ & D & Possible overkill \\
Professional Behavior & 3.57 & 4.65 & $76.63 \%$ & D & Possible overkill \\
\hline
\end{tabular}

Source: SPSS Output

Integrity is in quadrant $A$, meaning that the variable is considered particularly affect performance, including the elements that are considered very important. But GISA not execute as expected. So, Integrity should be the top priority in their duties. Secrecy entered in quadrant $B$, meaning that the variable has been successfully implemented by GISA very satisfactorily. So, it should always be maintained. Objectivity is in quadrant $\mathrm{C}$, meaning that the variable is considered less important influence on performance and unsatisfactory. So, it remains to be improved. In quadrant D, are competence, accountable and professional behaviour. This means that these three variables are considered less important in performance but GISA execute very satisfactorily

\section{Conclusion}

Based on calculations by Importance Performance Analysis as an Instrument Rating GISA performance result that 1) Performance has not been in line with expectations. 2) Integrity and Objectivity is the variable that performance is the lowest, it shall be increased or become a priority. While secrecy is satisfactory, then it must be maintained. Then competence, accountable and professional behaviour is the variable that has to do with excessive GISA.

\section{Commendations}

National and regional governments should have

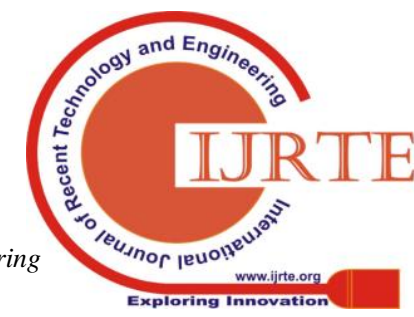


Implementation of Importance Performance Analysis Methods as Government Internal Supervisory Apparatus

(GISA) Performance Measurements in Indonesian Provinces

a strategy and policy to improve the integrity and objectivity of Government Internal Supervisory Apparatus (GISA), for example: 1) The selection process was held to recruit officials carried out as objectively as possible, using high standards and strict and honest implementation of the selection process. 2) Applying the principles of good governance. 3) Improved power system mechanisms of promotion, education and training, and supervision to give more participation to the community to do the apparatus. For example, by doing: a) education and leadership training. b) Education and functional training. c) education and technical training. d) Enforcement of disciplinary apparatus through provision of reward and punishment. e) Increased welfare apparatus according to subsistence

Ethical clearance - Not required

Source of funding- Self

Conflict of Interest - Nil

\section{References}

[1] Indonesian Government Internal Auditor Association. 2014 The Indonesian Government's Internal Auditor Code of Ethics.

[2] BPKP. 2013. Supervision News: Building good governance leads to clean government. BPKP Quarterly Magazine. Vol. XX / 110 / No? ISSN: 0854-0519.

2013. Supervision News: Building good governance leads to clean government. BPKP Quarterly Magazine. Vol. XX/110 / No? ISSN: 0854-0519.
2016. Government Internal Control System. http://www.bpkp.go.id/spip/ content / 400 / OverviewSPIP.bpkp

A dit Board of the Republic of Indonesia. 2013 Sharpening APIP's Role in Combating Corruption. Supervision News, Vol XX / No.3, September 2013. ISSN: 0854-0519.

2015. Summary of Results of the First Semester of 2015 Examination Jakarta, September 2015.

2014. Copies of Speeches of the President of the Republic of Indonesia at the Submission of the 2015 State Budget Bill along with Financial Notes August $\quad 15, \quad 2014 \quad-\quad 23: 31 \quad$ http://www.pikiranrakyat.com/nasional/2014/08/15/293148/salinan -speakers president-of-delivery-of-the-month-rafts-along with notes

President of the Republic of Indonesia. 2010. Republic of Indonesia Government Regulation Number 40 of 2010 concerning Amendments to Government Regulation Number 16 of 1994 concerning Functional Position of Civil Servants.

2010. Presidential Regulation of the Republic of Indonesia Number 54 of 2010 concerning Procurement of Government Goods / Services.

Auditor's Functional Development Center 2015 Profile of the Indonesian Government's Internal Auditor As of 30 November 2015. http: // pusbinjfa. bpkp.go.id/halaman/18

11] Martilla, J. and James, J. (1977), 'Importance-Performance Analysis', Journal of Marketing, 41 (1), 77-79.

APPENDIX

Suitability level

\begin{tabular}{|c|c|c|c|c|c|}
\hline Item & Indicators & Performance & Importance & Suitability level & Quadrant \\
\hline & Integritv: & & & & \\
\hline i1 & Honest & 3.41 & 4.80 & $71.04 \%$ & A \\
\hline i2 & Persevering & 3.40 & 4.77 & $71.28 \%$ & A \\
\hline i3 & To be responsible & 3.53 & 4.82 & $73.24 \%$ & B \\
\hline i4 & Obeying the law & 3.33 & 4.78 & $69.67 \%$ & A \\
\hline is & Organization goals & 3.46 & 4.62 & $74.89 \%$ & D \\
\hline i6 & Gratification & 3.18 & 4.75 & $66.95 \%$ & C \\
\hline & Average & 3.39 & 4.76 & $71.16 \%$ & \\
\hline & Objectivity: & & & & \\
\hline 01 & Conflict of interest & 3.35 & 4.59 & $72.98 \%$ & C \\
\hline 02 & Prejudice & 3.39 & 4.53 & $74.83 \%$ & C \\
\hline 03 & Professional responsibility & 3.42 & 4.60 & $74.35 \%$ & D \\
\hline 04 & Professional judgment & 3.37 & 4.61 & $73.10 \%$ & A \\
\hline 05 & Material facts. & 3.50 & 4.70 & $74.47 \%$ & B \\
\hline & Average & 3.41 & 4.61 & $73.95 \%$ & \\
\hline & Secrecy: & & & & \\
\hline s 1 & Use of in formation & 3.72 & 4.73 & $78.65 \%$ & B \\
\hline s2 & Protecting information & 3.71 & 4.73 & $78.44 \%$ & B \\
\hline s3 & Misuse of in formation 1 & 3.43 & 4.68 & $73.29 \%$ & C \\
\hline s4 & Misuse of in formation 2 & 3.52 & 4.76 & $73.95 \%$ & A \\
\hline s5 & Misuse of information 3 & 3.57 & 4.68 & $76.28 \%$ & C \\
\hline & Average & 3.59 & 4.72 & $76.12 \%$ & \\
\hline & Competence: & & & & \\
\hline c1 & Knowledge & 3.71 & 4.64 & $79.96 \%$ & A \\
\hline c2 & Expertise & 3.69 & 4.66 & $79.18 \%$ & B \\
\hline c3 & Skill & 3.64 & 4.64 & $78.45 \%$ & C \\
\hline c4 & Attitude behavior & 3.57 & 4.68 & $76.28 \%$ & D \\
\hline & Average & 3.65 & 4.66 & $78.46 \%$ & \\
\hline & Accountable: & & & & \\
\hline a 1 & $\begin{array}{l}\text { Ability deliver } \\
\text { accountability }\end{array}$ & 3.66 & 4.72 & $77.54 \%$ & B \\
\hline a2 & $\begin{array}{l}\text { Ability to answer to the } \\
\text { party entitled / authorized }\end{array}$ & 3.60 & 4.63 & $77.75 \%$ & C \\
\hline a3 & $\begin{array}{l}\text { The ability of a person's } \\
\text { performance and conduct }\end{array}$ & 3.67 & 4.63 & $79.27 \%$ & $\mathrm{D}$ \\
\hline & Average & 3.64 & 4.66 & $78.18 \%$ & \\
\hline & Professional behavior: & & & & \\
\hline p 1 & $\begin{array}{l}\text { Reputation of the } \\
\text { profession }\end{array}$ & 3.60 & 4.58 & $78.60 \%$ & D \\
\hline p2 & Illegal Activities & 3.49 & 4.70 & $74.26 \%$ & A \\
\hline p3 & Trust profession & 3.57 & 4.67 & $76.45 \%$ & B \\
\hline p4 & Consultation & 3.60 & 4.66 & $77.25 \%$ & B \\
\hline & Average & 3.57 & 4.65 & $76.63 \%$ & \\
\hline
\end{tabular}

